REEC - REVISTA ELETRÁNICA DE ENGENHARIA CIVIL $\quad$ Volume 8, No 1, 14-20

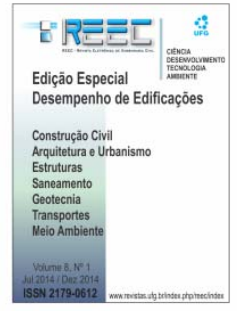

\title{
PARTIDA OPERACIONAL DE BIORREATOR COM MEMBRANAS (MBR): EPAR CAPIVARI II
}

\section{Operational start-up of a MBR: EPAR Capivari II}

\author{
Juliana Pontes Machado de Andrade, Luis Gustavo Alves de Lima, Renata de Lima Pereira de Gasperi, \\ Renato Rossetto ${ }^{1}$
}

Recebido em 15 de julho de 2013; recebido para revisão em 11 de agosto de 2013; aceito em 03 de dezembro de 2013; disponível on-line em 13 de fevereiro de 2014.

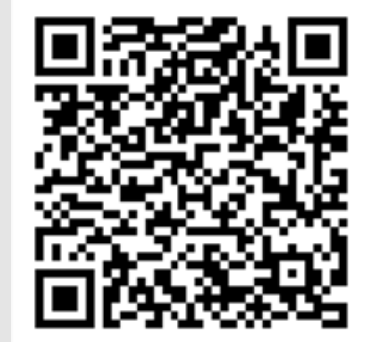

PALAVRAS CHAVES:

Ultrafiltração;

$M B R$;

Tratamento de Esgoto.

* Contato com o autor:

${ }^{1}$ e-mail : opera.esgoto@sanasa.com.br

Sociedade de Abastecimento de Água e Saneamento (SANASA).
RESUMO: Nos últimos anos a tecnologia que alia tratamento biológico com membranas filtrantes (MBR) vem sendo utilizada em muitos países para o tratamento avançado de esgoto doméstico. No Brasil, a SANASA foi a primeira empresa de saneamento a construir e operar estação com esta concepção. A partida operacional é um passo importante para o bom desempenho de uma estação de tratamento. Particularmente para o processo MBR, devem ser tomados alguns cuidados especiais devido às suas peculiaridades e alto grau de automatização. Este trabalho apresenta testes e atividades pré-operacionais, procedimentos transitórios além de resultados analíticos físico-químicos e bacteriológicos dos primeiros quatro meses de operação da planta. As análises apontam a rápida estabilização e confiabilidade do sistema bem como confirma a excelente qualidade da água de reuso produzida, com turbidez abaixo de 0,3 NTU e eficiência na remoção de DBO superior a 99,8\%.

\section{INTRODUÇÃO}

A Sociedade de Abastecimento de Água e Saneamento S/A. - SANASA, empresa responsável pelo saneamento básico no município de Campinas, adotou a opção do uso da tecnologia MBR Biorreator com Membranas de Ultrafiltração para Estação Produtora de Água de Reúso (EPAR) CAPIVARI II situada na região centro oeste do Município. Esta opção construtiva apresenta uma reduzida demanda de área para implantação do sistema e torna viável também a prática do reúso da água devido à elevada eficiência deste sistema. Esta estação terá um grande impacto gerando melhoria da qualidade de vida para a população, benefícios ao meio ambiente e a possibilidade de geração receita através da venda de água de reuso com elevada qualidade. A primeira etapa (Lote 1) entrou em operação em abril de 2012 e irá tratar uma vazão média de $182 \mathrm{~L} / \mathrm{s}$. A segunda etapa (Lote 2) irá dobrar a capacidade de tratamento.

Neste contexto al EPAR CAPIVARI II situada na bacia Hidrográfica do Rio Capivari torna-se um marco histórico, sendo a primeira estação deste porte na América Latina a adotar esta configuração para o tratamento de esgoto doméstico.

Este trabalho descreve as etapas do início de operação dessa planta, de maneira que possa ter utilidade para as próximas unidades que adotarem esta concepção. 


\section{METODOLOGIA}

A EPAR Capivari II está dividida nas seguintes unidades: gradeamento mecanizado com espaçamento de $15 \mathrm{~mm}$; peneira rotativa com malha circular e $2 \mathrm{~mm}$ de abertura; desarenador mecanizado; biorreator com subdivisões: anaeróbia, anóxica, aerada e desoxigenação; ultrafiltração por membranas submersas tipo fibra oca com poro nominal de 0,04 $\mu \mathrm{m}$ e desidratação mecanizada com centrífuga para a fase sólida (Figura 1). De Gasperi et al. (2011) apresentaram uma descrição mais detalhada deste projeto.

A partida da planta se deu em 3 etapas distintas. O início operacional se deu com o funcionamento do sistema de bombeamento composto por três estações elevatórias de esgoto em série (externas à planta) e do tratamento preliminar da EPAR. Na segunda etapa houve a partida do sistema biológico juntamente com a ultrafiltração. A última unidade a entrar em operação foi o sistema de desidratação. O foco deste trabalho é a partida do sistema biológico e ultrafiltração, que será detalhada a seguir.

\subsection{TESTES PRELIMINARES - SISTEMA DE ULTRAFILTRAÇÃO}

Antes da partida deste sistema foram tomados cuidados para garantir a segurança dos equipamentos, integridade das membranas e, consequentemente, a qualidade do efluente tratado. Para tanto foram realizados diversos testes, tais como: rotinas do sistema de supervisão e controle, verificação dos instrumentos de processo, teste de pressão e teste de bolhas. Todos os testes foram realizados com água e simultaneamente à partida do tratamento preliminar.

\subsubsection{Testes das rotinas do sistema de supervisão e controle}

O processo MBR funciona totalmente automatizado seguindo diversos modos de operação (por exemplo: produção, relaxamento, retrolavagem, limpezas químicas). Ele é controlado por um sistema de supervisão no qual estão programadas as rotinas do processo, incluindo: modos de operação, intertravamentos, alarmes e etc. Isso torna de extrema importância a verificação da programação (Figura 2).

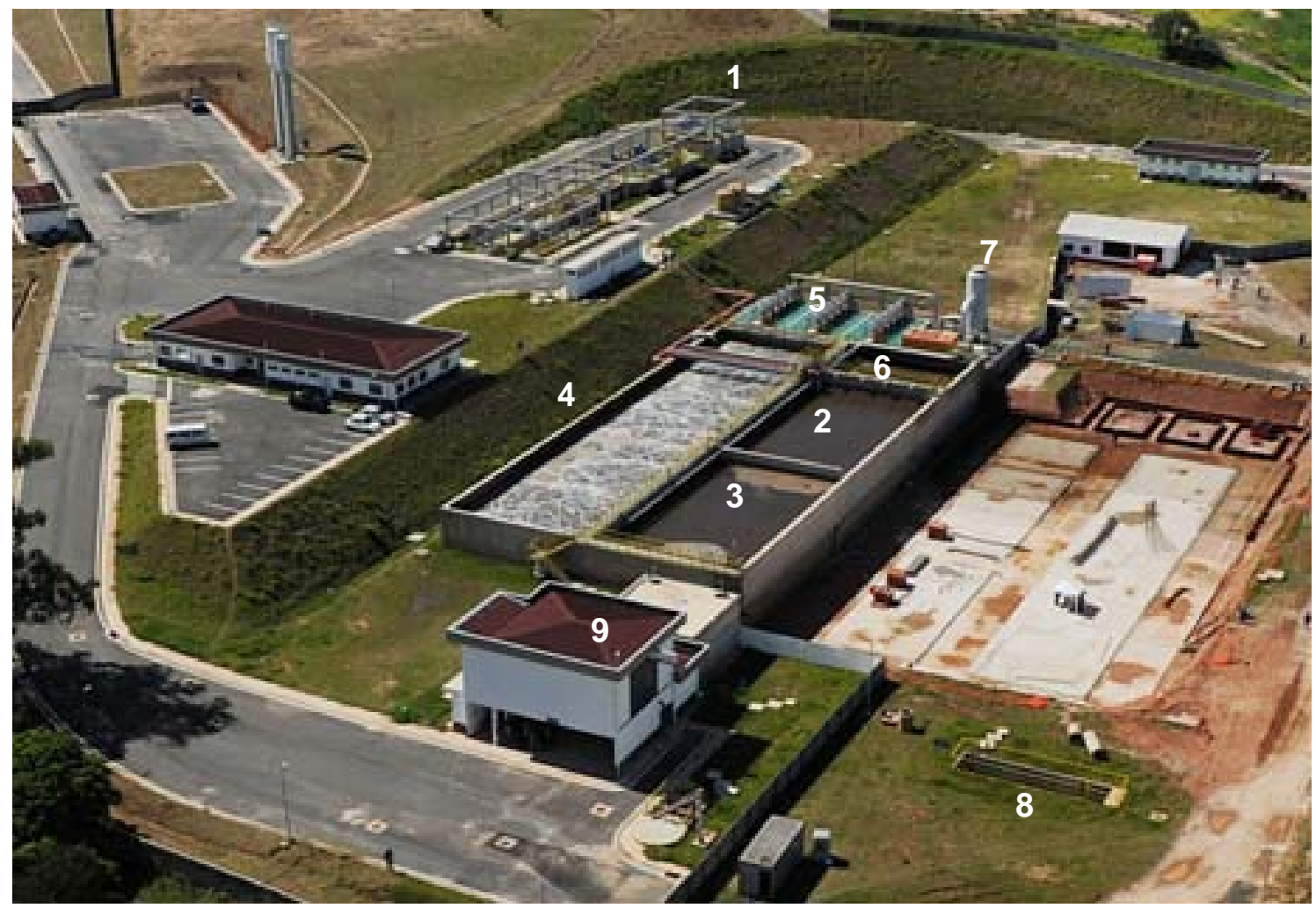

FIGURA 1: Foto aérea da EPAR Capivari II. Unidades: 1 - Tratamento Preliminar; 2 - Tanque anaeróbio; 3 Tanque anóxico; 4 - Tanque de aeração; 5 - Tanques de membranas; 6 - Tanque de desoxigenação; 7 - Tanque de permeado; 8 - Calha Parshall de saída; 9 - Prédio da desidratação. 


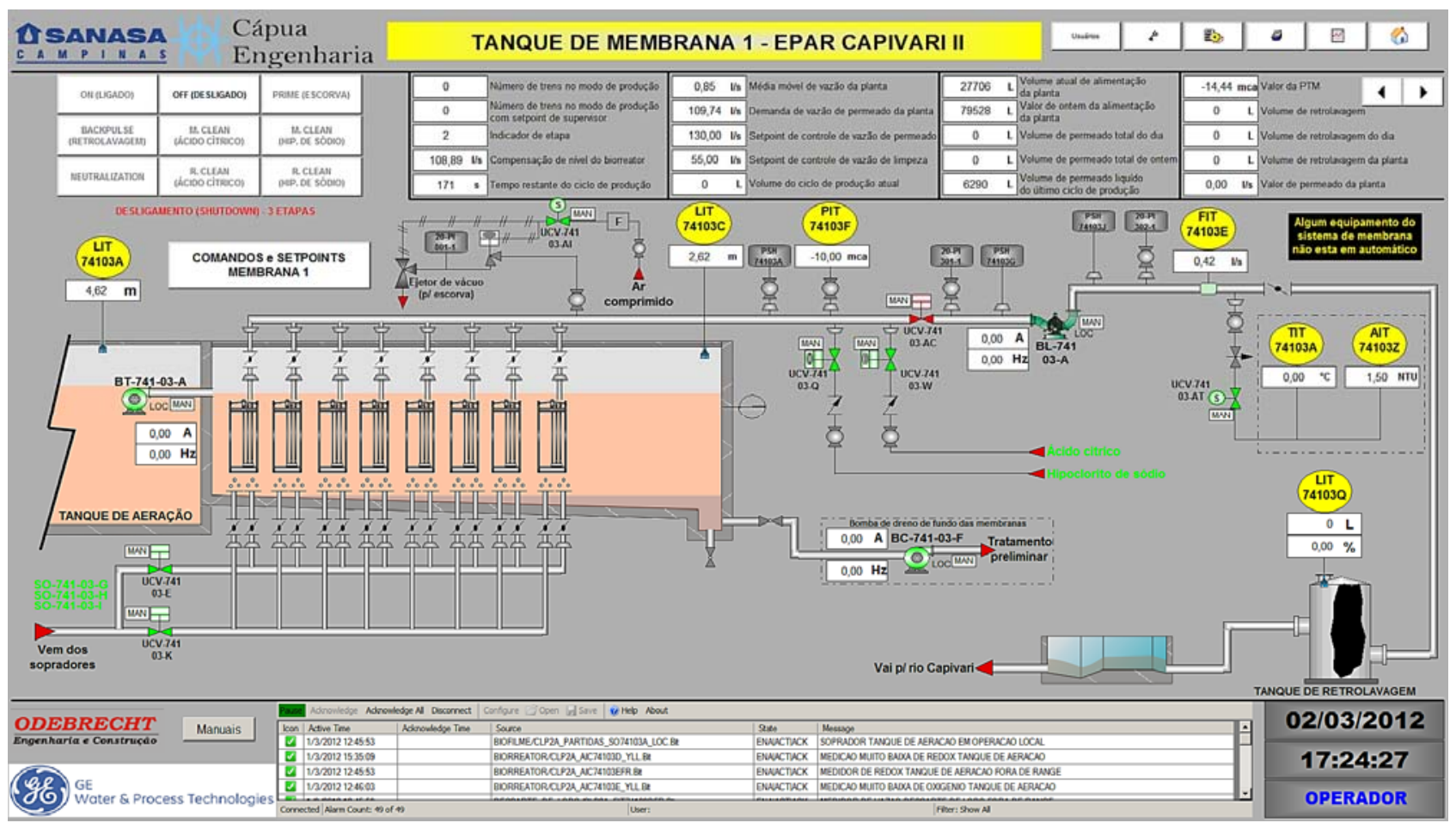

FIGURA 2: Exemplo de tela do sistema de supervisão e controle.

As informações necessárias para a programação deste sistema estão descritas em documentos de controle denominados: Narrativa de Controle, Tabela de Sequência das Operações e Quadro Resumo da Lógica de Controle (GE WATER \& PROCESS TECHNOLOGIES, 2011).

Os testes foram então realizados comparando o que estava sendo executado pelo software com o descrito nos documentos de controle. Para tanto foram simuladas condições normais de operação e também condições extremas (ex: pressão transmembrana alta, turbidez alta, vazão baixa, etc) checando os intertravamentos e condições de falhas de modo a avaliar a segurança do sistema.

\subsubsection{Teste de bolhas}

O teste de bolhas é utilizado para localizar eventuais pontos de vazamentos nas fibras das membranas que necessitem de reparo.

Resumidamente 0 teste consiste na aplicação de uma pressão controlada de ar comprido na conexão de permeado de cada cassete, com o cassete submerso em água (Figura 3). Caso haja vazamentos, haverá desprendimento de bolhas. Dependendo do tipo e tamanho das bolhas é possível inferir o grau de severidade do vazamento e identificar quais necessitam ser reparados.

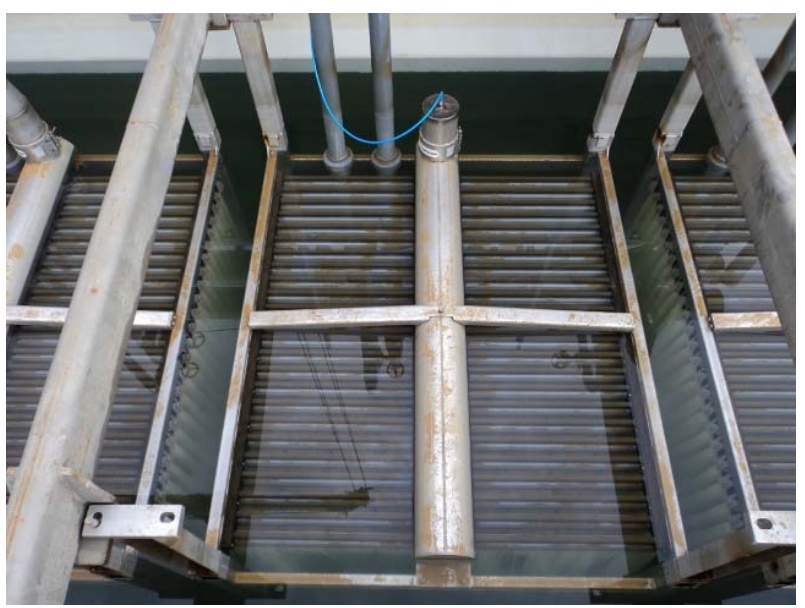

FIGURA 3: Cassete de membranas com dispositivo de aplicação de ar comprimido para realização de teste de bolhas - EPAR Capivari II.

\subsection{PARTIDA MBR}

Ao final dos testes parte da água que estava no sistema biológico foi drenada para início da operação da unidade.

Em abril de 2012 foi feita a inoculação do 
sistema com lodo aeróbio proveniente de estações de tratamento de esgoto (ETE's) da SANASA (cerca de $680 \mathrm{~m}^{3}$ de lodo com $0,5 \%$ teor de sólidos). Este lodo precisou ser peneirado para garantir que nenhum resíduo superior a $2 \mathrm{~mm}$ adentrasse no sistema biológico e viesse a causar danos às membranas de ultrafiltração (Figura 4).

Durante os primeiros dias foi necessário manter o soprador do tanque de aeração com funcionamento intermitente, com vistas a minimizar a formação de espuma.

Devido à vazão média afluente à planta (35 L/s) ser inferior à média de projeto $(180 \mathrm{~L} / \mathrm{s})$, sendo uma das consequências o aumento do tempo de detenção hidráulica (TDH), foram adotados procedimentos transitórios para a rotina operacional que devem ser mantidos até o aumento da vazão com a finalização das obras do lote 2.

Visando um TDH menor, a lâmina líquida do sistema biológico foi reduzida a $80 \%$ do valor recomendado em projeto. Esta manobra foi possível pois a transferência do licor misto do tanque de aeração para os tanques de membranas é feita através de bombas e a vazão de saída do efluente do sistema é variável.
Além disso, devido à baixa carga afluente e para manter a relação $\mathrm{F} / \mathrm{M}$ (alimento / microorganismos) de projeto, buscou-se trabalhar com a concentração de sólidos suspensos totais entre 3500 - 4000 mg/L (também abaixo do valor projetado: $8000 \mathrm{mg} / \mathrm{L})$.

Quanto à ultrafiltração, inicialmente apenas um dos três tanques de membranas foi colocado em operação. Este tanque teve seu tempo de funcionamento e vazão de trabalho ajustados para que o fluxo se aproximasse do valor de projeto (19 LMH para vazão média). As membranas de ultrafiltração necessitam de limpezas químicas para tentar reduzir o impacto causado por substâncias incrustantes. Para as membranas ZeeWeed ${ }^{\circledR}$ há dois tipos de limpeza: de manutenção (mais suave) e de recuperação (mais intensa). Na EPAR Capivari II, as limpezas de manutenção com hipoclorito de sódio foram iniciadas em maio/2012 com frequência semanal.

Quando o sistema entrou em operação, passou-se a analisar o esgoto bruto e o efluente permeado. Todas as análises foram realizadas na SANASA, sendo as físico-químicas no Laboratório de Análise e Controle de Efluentes (TSC) e as bacteriológicas no Laboratório Central (TAL).

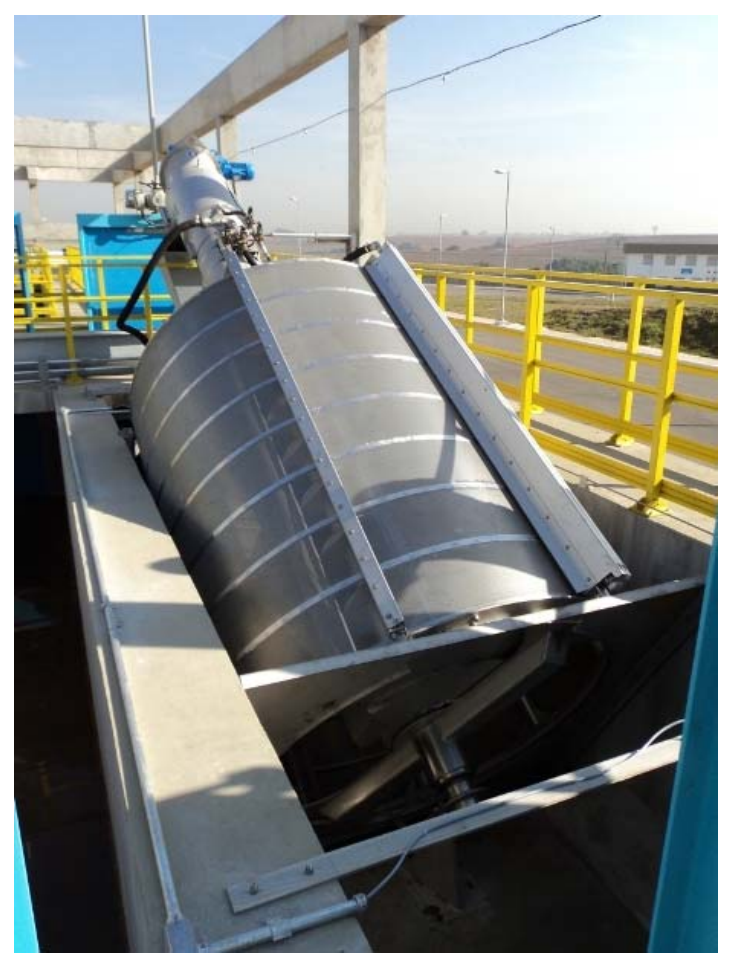

FIGURA 4: Peneira rotativa com malha de $2 \mathrm{~mm}$ - EPAR Capivari II. 


\section{RESULTADOS}

Os testes de rotinas de programação, bem como da atuação dos instrumentos de processo apontaram a necessidade de calibrações nos instrumentos e ajustes no programa.

Com o teste de bolhas (Figura 5), realizado nos três tanques de membranas, foram mapeados os pontos que precisavam ser reparados nas fibras de membranas. Estes pontos são aqueles que apresentam bolhas grossas de ar saindo pela parede da fibra ou pelos encaixes devido a problemas nos anéis de vedação.

De posse desse mapeamento, foi realizado o reparo que consiste em identificar exatamente $o$ ponto de vazamento e injetar silicone especial para vedá-lo (Figura 6).

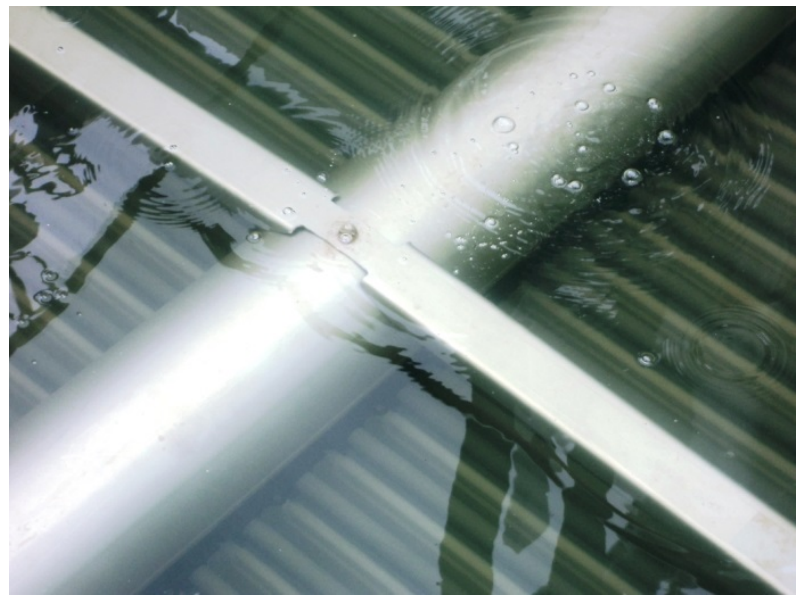

FIGURA 5: Bolhas observadas durante os testes.
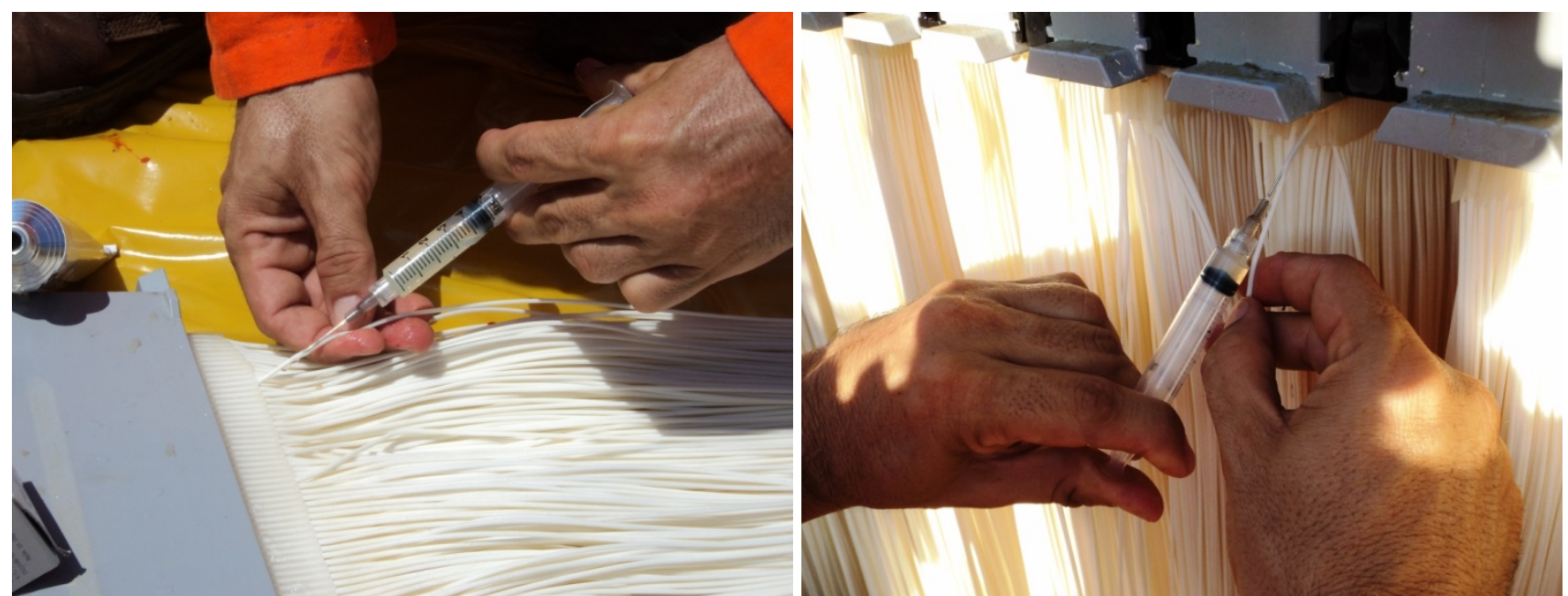

FIGURA 6: Reparo das membranas realizado com módulo retirado do cassete (esquerda) e módulo instalado no cassete (direita).

Após a realização dos reparos foi dado início ao processo de inoculação e a admissão de esgoto foi liberada para o sistema biológico. Após 3 dias iniciou-se o processo de ultrafiltração. Neste intervalo, o esgoto foi acumulado e recirculado nos reatores do sistema, ou seja, sendo tratado biologicamente.

Com a redução do TDH evitou-se alterações das condições de alcalinidade e pH que poderiam interferir no desenvolvimento da biomassa do sistema.

Quanto ao sistema de ultrafiltração, a pressão transmembrana inicial estava em torno de
0,3 m.c.a. e se manteve neste patamar durante o período analisado neste trabalho.

O ciclo de filtração inicialmente previsto para a planta era 8 minutos com uma retrolavagem programada a cada 2 relaxamentos. Devido às condições iniciais com vazão e SSTA reduzidas, foi possível alterar a duração do clico para 12 minutos e a relação relaxamento $x$ retrolavagem passou para $10 \times 1$.

A Tabela 1 mostra os resultados das análises realizadas durante os primeiros quatro meses de operação. 
TABELA 1: Resultados das análises físico-químicas e bacteriológica do esgoto bruto e efluente tratado pela EPAR Capivari II de abril a julho / 2012.

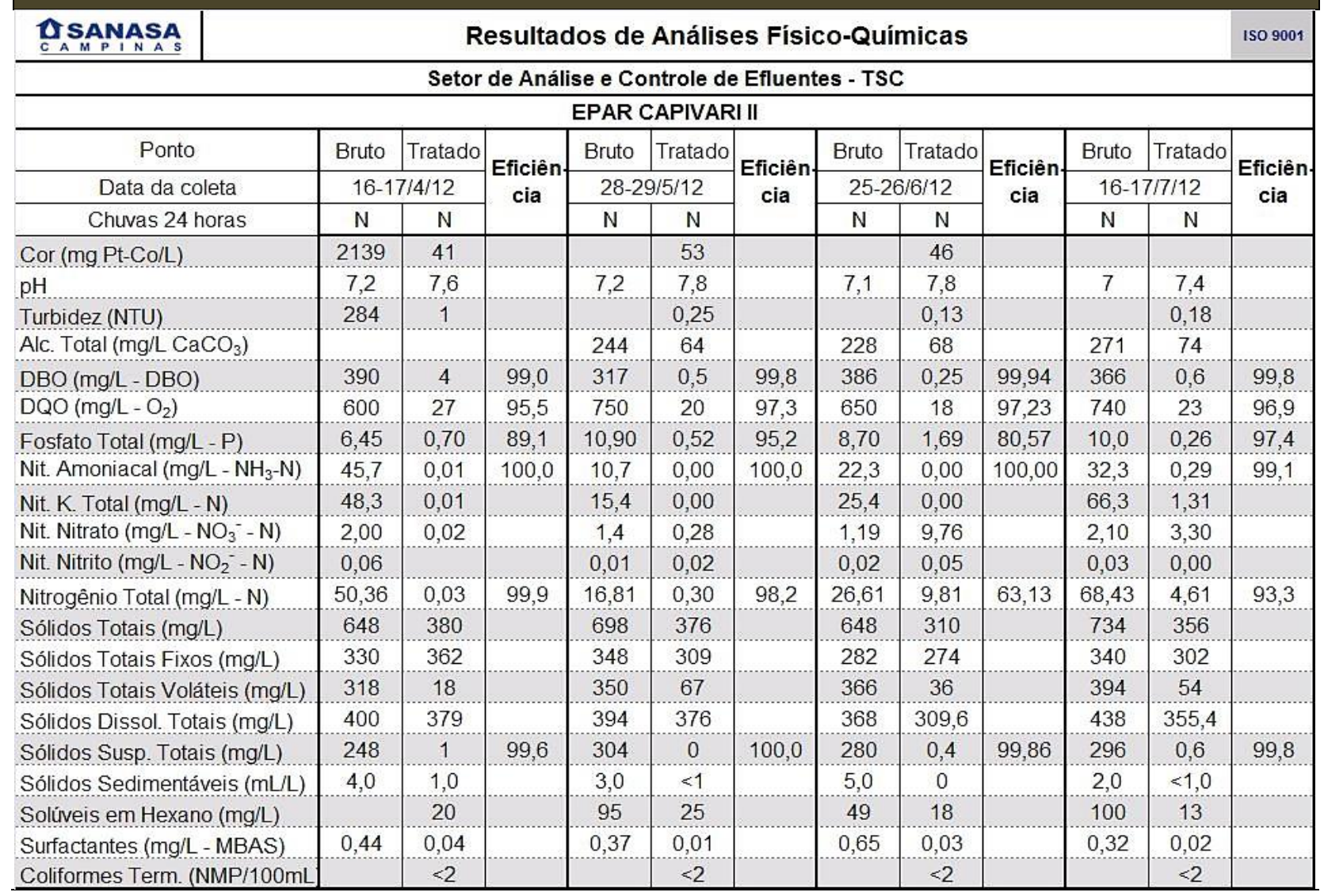

\section{DISCUSSÃO}

Os cuidados tomados com o sistema de automação anteriores à partida proporcionaram a correção antecipada de problemas, evitando necessidade de paradas após a entrada da planta em operação.

Os testes de pressão e bolhas em conjunto com o reparo das fibras foram exitosos, tal fato é perceptível nos baixos valores de turbidez do efluente tratado (<0,3 NTU).

A alcalinidade do esgoto bruto contribuiu para a manutenção das condições favoráveis de pH para o desenvolvimento da biomassa e desnitrificação sem a necessidade de adicionar produtos químicos.

Os demais resultados da Tabela 1 comprovam a rápida estabilização e ótima eficiência do sistema em relação aos principais parâmetros de qualidade adotados para avaliação do tratamento. A DBO do efluente tratado foi $4 \mathrm{mg} / \mathrm{L}$ já na primeira semana de operação e em seguida se manteve inferior a $1 \mathrm{mg} / \mathrm{L}$; a eficiência de remoção superou $99 \%$ desde a 1 ạ semana e foi igual ou superior a 99,8\% nas demais amostras. Em relação à DQO, SST e NH3-N as eficiências superaram 95\%, 99,6\% e 99,1\% respectivamente.

Salienta-se que os resultados das análises de coliformes termotolerantes no efluente tratado ficaram dentro da incerteza do método (<2NMP/100mL), mesmo sem a utilização de produtos químicos. Este resultado foi atingido devido à barreira física imposta pelas membranas, pois o tamanho de seus poros $(0,04 \mu \mathrm{m})$ não permite a passagem daqueles microrganismos e diversos outros que possuem dimensões superiores ao poro.

Em geral, os resultados físico-químicos e bacteriológicos comprovam a excelente qualidade do efluente tratado na planta.

\section{CONCLUSÃO}

A partida operacional de uma estação de produção de água de reuso requer certos cuidados 
que podem ser desnecessários em outros tipos de estação de tratamento de esgotos. Especial atenção ao tipo de lodo a ser inoculado, bem como o peneiramento do mesmo são aspectos que não podem ser ignorados devido ao aspecto de filtrabilidade e risco de entrada no sistema de material que possa danificar as fibras.

Deve-se atentar também para a confiabilidade do sistema de supervisão e das medições de instrumentos de processo; pois o sistema conta com alto grau de automatização.

Além disso, como em todas as plantas, operacionalmente é necessário adotar uma rotina modificada para o período de pouca carga.

De uma maneira geral, com todos os cuidados tomados na partida o sistema demonstrou estabilidade e confiabilidade nos resultados, além de simplicidade operacional desde o início.

As análises características físico-químicas e bacteriológicas iniciais do efluente tratado na planta o capacitam como potencial fonte de água para uso não potável em diversos fins. Além disso, caso não seja aproveitado diretamente em outras atividades, este efluente contribui fortemente para a melhoria das condições do corpo d'água receptor (Rio Capivari).

\section{AGRADECIMENTOS}

À equipe operacional da estação; aos laboratórios da SANASA: Laboratório de Análise e Controle de Efluentes (TSC) pela realização das análises físico-químicas e Laboratório Central (TAL) pelas análises bacteriológicas.

\section{REFERÊNCIAS BIBLIOGRÁFICAS}

DE GASPERI, R.L.P. et al. Uso de membranas para a produção de água de reúso em Campinas - SP. In: XV EXPOSIÇÃO DE EXPERIÊNCIAS MUNICIPAIS EM SANEAMENTO, 2011, Campinas - SP. 41a. Assembleia Nacional da ASSEMAE. 2011, 13p.

EMA ENGENHARIA AMBIENTAL Projeto Executivo Hidráulico - Estação Produtora de Água de Reúso EPAR - Sistema Capivari II, Revisão 3. 2010 Campinas, São Paulo.
GE WATER \& PROCESS TECHNOLOGIES Manual de Operação e Manutenção - Sistema Modular de Tratamento de Efluentes e Água ZeeWeed. 2011. 